\title{
Effect of isoflurane versus propofol-remifentanil anesthesia on neuromuscular blockade and hemodynamic responses by cisatracurium bolus injection
}

\author{
Dongho Hyun, Han-Bom Ryu, and Mi-Woon Kim \\ Department of Anesthesiology and Pain Medicine, Gyeongju Hospital, College of Medicine, Dongguk University, Gyeongju, Korea
}

Background: Inhalational anesthetics potentiate nondepolarizing muscle relaxants. Cisatracurium is a recently introduced neuromuscular blocker in Korea. We studied the effect of inhalational anesthesia and total intravenous anesthesia (TIVA) on neuromuscular blockades and hemodynamic responses by cisatracurium bolus injection.

Methods: Forty patients undergoing elective surgery were randomly divided into isoflurane and propofolremifentanil groups. A bolus dose of cisatracurium of $0.15 \mathrm{mg} / \mathrm{kg}\left(3 \times \mathrm{ED}_{95}\right)$ was administered after induction and the onset time and clinical duration of action were recorded. The nueromuscular blockade was monitored using train-offour (TOF) stimulation. Hemodynamic parameters were also recorded.

Results: Onset time was $194.0 \pm 39.1 \mathrm{sec}$ in the isoflurane group and $226.5 \pm 62.2 \mathrm{sec}$ in the propofol-remifentanil group. Clinical duration of action was $49.2 \pm 9.0 \mathrm{~min}$ in the isoflurane group and $43.0 \pm 9.2 \mathrm{~min}$ in the propofolremifentanil group. Systolic blood pressure (SBP) and diastolic blood pressure (DBP) immediately before intubation decreased in the propofol-remifentanil group. Heart rate (HR), SBP and DBP 1 and 3 min after tracheal intubation increased in the isoflurane group.

Conclusions: Onset time was similar between isoflurane and propofol-remifentanil anesthesia. Clinical duration of action was significantly longer in isoflurane anesthesia. SBP and DBP immediately before intubation and HR, SBP and DBP 1 and 3 min after tracheal intubation were significantly different between the two groups. (Korean J Anesthesiol 2011; 61:297-301)

Key Words: Cisatracurium, Isoflurane, Propofol, Remifentanil.

Received: February 23, 2011. Revised: March 23, 2011. Accepted: April 25, 2011.

Corresponding author: Mi-Woon Kim, M.D., Ph.D., Department of Anesthesiology and Pain Medicine, Gyeongju Hospital, College of Medicine, Dongguk University, 1090-1, Seokjang-dong, Gyeongju 780-350, Korea. Tel: 82-54-770-8271, Fax: 82-54-770-8500, E-mail: swankim@dongguk.ac.kr (c) This is an open-access article distributed under the terms of the Creative Commons Attribution Non-Commercial License (http:// creativecommons.org/licenses/by-nc/3.0/), which permits unrestricted non-commercial use, distribution, and reproduction in any medium, provided the original work is properly cited. 


\section{Introduction}

Cisatracurium is a new neuromuscular blocker in Korea with characteristic organ independent Hofmann elimination. Cisatracurium does not produce plasma histamine and does not affect HR or blood pressure [1]. Cisatracurium is also effective for intubation by $3 \times \mathrm{ED}_{95}$ or $4 \times \mathrm{ED}_{95}$ bolus injection. Cisatracurium has a duration of action of $45 \mathrm{~min}$ after a $0.1 \mathrm{mg} /$ $\mathrm{kg}$ dose and approximately $68 \mathrm{~min}$ after $0.2 \mathrm{mg} / \mathrm{kg}$ [2].

Inhalational anesthetics are known to affect the pharmacodynamics of neuromuscular blockers [3], and enhance the effect of neuromuscular blockers more than intravenous anesthetics such as propofol [4]. Several studies have been conducted to evaluate the onset time and duration of action of cisatracurium [1,5-8]. However, there are a few studies about the onset time of cisatracurium with concomitant use of inhalational anesthetics [9].

This study was designed to compare the effect of isoflurane and propofol-remifentanil anesthesia on neuromuscular blockade (onset time, clinical duration of action) and hemodynamic responses by cisatracurium bolus injection $(3 \times$ $\left.\mathrm{ED}_{95}\right)$.

\section{Materials and Methods}

After obtaining informed written consent approved by the Institutional Review Board, 40 patients, American Society of Anesthesiologists (ASA) physical status I or II, undergoing elective surgery and requiring general anesthesia were admitted to this prospective randomized study. All patients had no medical history of malignant hyperthermia, hypersensitivity to neuromuscular blockers, alcoholism, drug addiction, psychiatric, neuromuscular, cardiovascular, renal, or hepatic impairments. Patients were excluded if they had recently taken drugs known to affect neuromuscular function. Standard monitoring including peripheral oxygen saturation, heart rate (HR), non-invasive blood pressure, ECG, end-tidal carbon dioxide concentration and body temperature. Patients were randomized in two groups. Isoflurane group $(n=20$ patients) received propofol $2 \mathrm{mg} / \mathrm{kg}$ for anesthetic induction. After loss of eyelash reflex $50 \% \mathrm{~N}_{2} \mathrm{O}$ in $\mathrm{O}_{2}$ and $4 \mathrm{Vol} \%$ (delivered concentration) of isoflurane were inhaled until tracheal intubation. After intubation anesthesia was maintained with $50 \% \mathrm{~N}_{2} \mathrm{O}$ in $\mathrm{O}_{2}$ and $1-1.5 \mathrm{Vol} \%$ (end tidal concentration) of isoflurane. Propofol-remifentanil group ( $n=20$ patients) received propofol and remifentanil for anesthetic induction and maintenance by using effect site target concentration infusion (TCI, Orchestra ${ }^{\mathrm{TM}}$, Fresinius Vial, France). $5 \mu \mathrm{g} / \mathrm{ml}$ of propofol and $5 \mathrm{ng} / \mathrm{ml}$ of remifentanil were started with $100 \%$ $\mathrm{O}_{2}$ until tracheal intubation. After intubation anesthesia was maintained with $50 \% \mathrm{~N}_{2} \mathrm{O}$ in $\mathrm{O}_{2}$ and $3 \mu \mathrm{g} / \mathrm{ml}$ of propofol and $1-3 \mathrm{ng} / \mathrm{ml}$ of remifentanil. After loss of eyelash reflex, both groups received a bolus dose of cisatracurium of $0.15 \mathrm{mg} /$ $\mathrm{kg}$ over $5 \mathrm{sec}$. Tracheal intubation was performed by one anesthesiologist when the response to TOF stimulation was completely ablated. Neuromuscular blockade was assessed by tactile response of the adductor pollicis brevis muscle to TOF stimulation produced by peripheral nerve stimulator (Dual Stim $^{\mathrm{TM}}$, Life-Tech, USA). Evaluation of tactile responses was performed by the same independent anesthesiologist. Surface electrodes were applied over the ulnar nerve at the wrist, and the ulnar nerve was stimulated supramaximally with repeated TOF stimuli ( $2 \mathrm{~Hz}$ for $2 \mathrm{sec}$ at 10 -sec intervals). Tidal volume and respiratory rate were controlled to maintain the endtidal carbon dioxide concentration between 30 and $35 \mathrm{mmHg}$. Heating blankets and warm forced air devices were used to maintain esophageal temperature between 35 and $37^{\circ} \mathrm{C}$. The hand, where neuromuscular transmission was assessed, was wrapped in cotton wool to minimize heat loss. The duration from completion of cisatracurium injection to ablation of first twitch response to TOF was defined as onset time and duration from ablation of first twitch response to TOF to reappearance of third twitch response to TOF was defined as clinical duration of action. Hemodynamic parameters such as HR, SBP, DBP were measured immediately before induction, immediately before tracheal intubation and 1, 3, 5 and 10 min after tracheal intubation.

Prior to the study, a power analysis indicated that $\alpha$ was set to 0.05 , and $\beta$ was set to 0.20 . This power analysis required 40 patients, with 20 patients in each group. Statistical analyses were performed with SPSS 12.0 for Windows (SPSS Inc, Chicago, IL, USA). Statistical significance was set at $\mathrm{P}<0.05$. Chi-square test was used for inter-group comparison of gender. Unpaired $\mathrm{T}$ test was used to compare age, height, weight and measurement between the two groups. Repeated measures ANOVA was used to compare the measurement within the same group. All data were presented as means \pm standard deviation (SD).

\section{Results}

There were no significant differences between the two groups in age, sex, height, weight, and ASA physical status (Table 1). Onset time was $194.0 \pm 39.1 \mathrm{sec}$ in the isoflurane group and $226.5 \pm 62.2 \mathrm{sec}$ in the propofol-remifentanil group ( $\mathrm{P}>0.05$ ). Onset time was not different between the two groups. Clinical duration of action was $49.2 \pm 9.0 \mathrm{~min}$ in the isoflurane group and $43.0 \pm 9.2 \mathrm{~min}$ in the propofol-remifentanil group $(\mathrm{P}<0.05)$. The clinical duration of action was significantly longer in the isoflurane group (Table 2).

Hemodynamic parameters such as HR, SBP and DBP were 
Table 1. Demographic Data

\begin{tabular}{lcc}
\hline & iso group $(\mathrm{n}=20)$ & $\mathrm{p} / \mathrm{r}$ group $(\mathrm{n}=20)$ \\
\hline Age $(\mathrm{yr})$ & $47.6 \pm 14.8$ & $38.5 \pm 17.8$ \\
Weight $(\mathrm{kg})$ & $62.7 \pm 13.4$ & $59.1 \pm 10.6$ \\
Height $(\mathrm{cm})$ & $162.7 \pm 9.8$ & $160.9 \pm 6.5$ \\
Sex $(\mathrm{M} / \mathrm{F})$ & $8 / 12$ & $6 / 14$ \\
\hline
\end{tabular}

Values are number of patients or mean \pm SD. iso group: isoflurane group, $\mathrm{p} / \mathrm{r}$ group: propofol-remifentanil group.

A
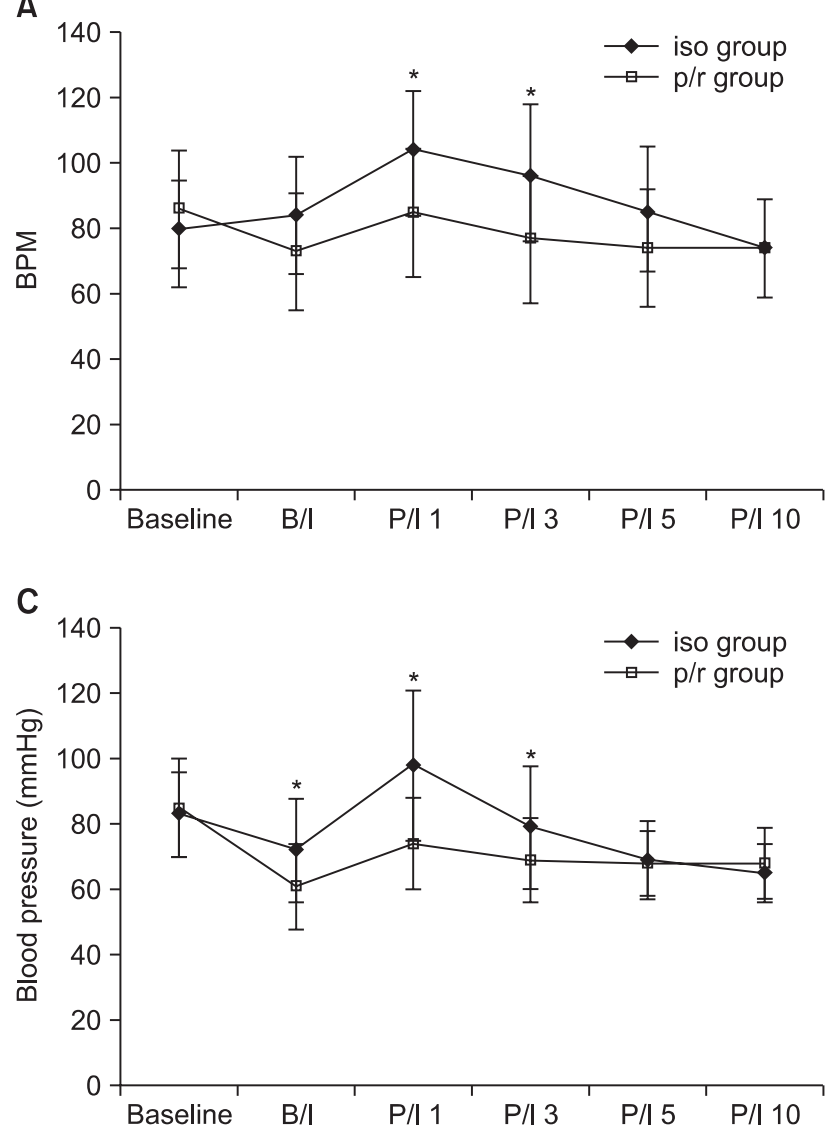

not different between the two groups immediately before induction. SBP and DBP immediately before intubation decreased in the propofol-remifentanil group compared to the isoflurane group $(\mathrm{P}<0.05)$. HR, SBP and DBP 1 and 3 min after tracheal intubation increased in the isoflurane group $(\mathrm{P}<0.05)$ (Fig. 1).

\section{Discussion}

Cisatracurium is an intermediate acting neuromuscular blocker using specific metabolic processes. It is primarily cleared from the body by Hofmann elimination (77\%) and renal excretion (16\%) [10]. Since Hofmann elimination is an organindependent chemodegradative mechanism, there is little or
Table 2. Onset Time and Duration of Action

\begin{tabular}{lcc}
\hline & iso group & $\mathrm{p} / \mathrm{r}$ group \\
\hline Onset time (sec) & $194.0 \pm 39.1$ & $226.5 \pm 62.2$ \\
Duration of action (min) & $49.2 \pm 9.0^{*}$ & $43.0 \pm 9.2$ \\
\hline
\end{tabular}

Values are mean $\pm \mathrm{SD}$. iso group: isoflurane group, $\mathrm{p} / \mathrm{r}$ group: propofol-remifentanil group. ${ }^{*} \mathrm{P}<0.05$.

B

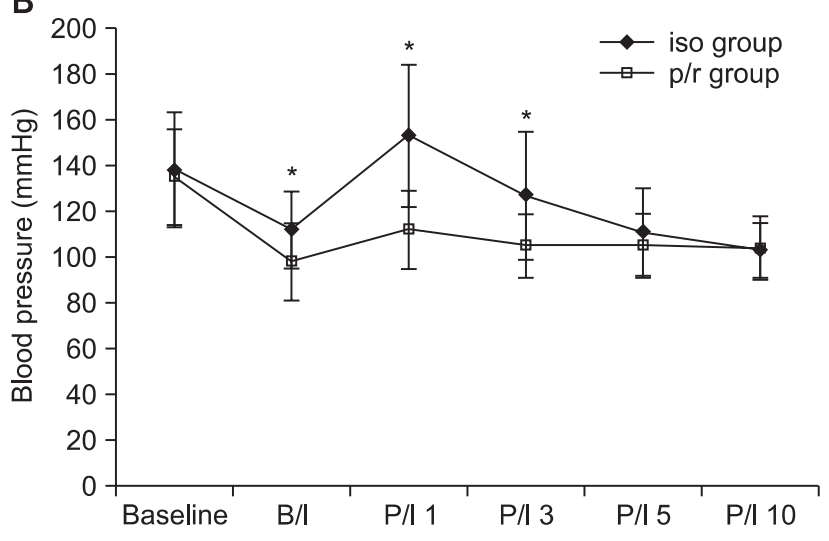

Fig. 1. Hemodynamic Results. Heart rate (A), systolic blood pressure (B) and diastolic blood pressure (C). iso group: isoflurane group, $p$ / $r$ group: propofol-remifentanil group, BPM: beats per minute, B/ I: before intubation, $\mathrm{P} / \mathrm{I} 1$ : postintabion $1 \mathrm{~min}, \mathrm{P} / \mathrm{I}$ 3: postintabion $3 \mathrm{~min}, \mathrm{P} / \mathrm{I}$ 5: postintabion $5 \mathrm{~min}, \mathrm{P} / \mathrm{I}$ 10: postintabion $10 \mathrm{~min} .{ }^{*} \mathrm{P}<$ 0.05. Compared between iso group and $\mathrm{p} / \mathrm{r}$ group.

no risk of the use of cisatracurium in patients with liver or renal disease when compared with other neuromuscular blockers.

Inhalational anesthetics potentiate neuromuscular blockades mainly through a postsynaptic effect [11]. Duration of inhalational anesthetics critically influences neuromuscular effects of nondepolarizing muscle relaxants. This potentiation depends on time and concentration [12]. Neuromuscular blocking effect of cisatracurium is enhanced by desflurane, sevoflurane and isoflurane to a similar extent [13].

In this study we assessed the neuromuscular blockade by using the number of tactile response to TOF stimulation. Kopman reported that when the fourth evoked response to TOF stimulation was first palpable, the mean height of first of four TOF twitches value was $37 \pm 8.5 \%$ (standard deviation) of 
control within a range of $20-70 \%$ [14]. Kirkegaard et al. [15] reported that the mechanomyographic magnitude of the first TOF twitch measured at reappearance of each of the four tactile TOF responses were $4 \%$ (1st), 12\% (2nd), 24\% (3rd) and $26 \%$ (4th). Because counting the number of tactile response to TOF stimulation is subjective, we assessed neuromuscular blockades by the same independent anesthesiologist.

Bluestein et al. [5] reported that increasing the initial dose of cisatracurium (from 0.1 to 0.15 and $0.2 \mathrm{mg} / \mathrm{kg}$ ), decreased the mean time of onset (from 4.6 to 3.4 and $2.8 \mathrm{~min}$, respectively) and increased the mean time of clinically effective duration (45 to 55 and $61 \mathrm{~min}$, respectively). Doenicke et al. [6] reported that when administered immediately after thiopental, cisatracurium had faster onset time $(105 \pm 41 \mathrm{sec}$ in $0.15 \mathrm{mg} / \mathrm{kg}$ and $68 \pm 19 \mathrm{sec}$ in $0.25 \mathrm{mg} / \mathrm{kg}$ ).

In our study, mean onset time of $0.15 \mathrm{mg} / \mathrm{kg}\left(3 \times \mathrm{ED}_{95}\right)$ of cisatracurium was $32 \mathrm{sec}$ longer in the propofol-remifentanil group. This result was not statistically different but small amount of inhaled isoflurane may slightly affect the onset time of cisatracurium. We recommend performing tracheal intubation at least $3.5 \mathrm{~min}$ after $0.15 \mathrm{mg} / \mathrm{kg}\left(3 \times \mathrm{ED}_{95}\right)$ of cisatracurium bolus injection.

Because of the relatively longer onset time of cisatracurium, the remifentanil dose must be reduced during induction period. We used a target controlled infusion of propofol-remifentanil in the propofol-remifentanil group, and the target of propofol was kept at $5 \mu \mathrm{g} / \mathrm{ml}$ until tracheal intubation and kept unchanged at $3 \mu \mathrm{g} / \mathrm{ml}$ in each patient during the maintenance of anesthesia for the entire study period. The target of remifentanil was kept at $5 \mathrm{ng} / \mathrm{ml}$ until tracheal intubation and kept between $1-3 \mathrm{ng} /$ $\mathrm{ml}$ for maintaining stable blood pressure. Remifentanil was not known to affect the level of neuromuscular blockade [16].

Dose of cisatracurium may be selected based on the desired time of intubation and the anticipated length of surgery. Doses of $0.15 \mathrm{mg} / \mathrm{kg}\left(3 \times \mathrm{ED}_{95}\right)$ and $0.20 \mathrm{mg} / \mathrm{kg}\left(4 \times \mathrm{ED}_{95}\right)$ of cisatracurium may produce generally good or excellent condition of intubation (3.4 and $2.8 \mathrm{~min}$ ) and clinically effective duration(55 and $61 \mathrm{~min}$ ) respectively [17].

In our study, we defined the clinical duration of action as duration from ablation of first twitch response to TOF to reappearance of third twitch response to TOF. It was $49.2 \pm 9.0$ $\mathrm{min}$ in the isoflurane group and $43.0 \pm 9.2 \mathrm{~min}$ in the propofolremifentanil group. This was relatively short from the other studies, because clinically using tactile count to TOF does not match mechanomyographic or acceleromyographic TOF recovery [18].

Nitrous oxide does not affect cisatracurium demand when using closed-loop computerized infusion of the muscle relaxant with the aim of maintaining a stable $90 \%$ neuromuscular block [19]. However, it potentiates inhalational anesthetics rather than intravenous anesthetics.

Cisatracurium does not produce plasma histamine and has excellent cardiovascular stability $[1,6]$. SBP and DBP immediately before intubation decreased more in the propofolremifentanil group and $\mathrm{HR}, \mathrm{SBP}$ and $\mathrm{DBP} 1$ and $3 \mathrm{~min}$ after tracheal intubation increased in the isoflurane group. These hemodynamic differences probably resulted from the interaction between cisatracurium and induction agents.

We studied the effect of isoflurane and propofol-remifentanil anesthesia on neuromuscular blockades and hemodynamic responses by cisatracurium bolus injection. The onset time of cisatracurim was not different between the two groups because of the short duration of inhalation of isoflurane, but the clinical duration of cisatracurium bolus injection was significantly longer in the inhalational anesthesia group rather than the total intravenous anesthesia group.

\section{References}

1. Lien CA, Belmont MR, Abalos A, Eppich L, Quessy S, Abou-Donia $\mathrm{MM}$, et al. The cardiovascular effects and histamine-releasing properties of 51W89 in patients receiving nitrous oxide/opioid/ barbiturate anesthesia. Anesthesiology 1995; 82: 1131-8.

2. Belmont MR, Lien CA, Quessy S, Abou-Donia MM, Abalos A, Eppich L, et al. The clinical neuromuscular pharmacology of 51W89 in patients receiving nitrous oxide/opioid/barbiturate anesthesia. Anesthesiology 1995; 82: 1139-45.

3. Eger EI. Uptake and distribution. In: Miller's Anesthesia. 7th ed. Edited by Miller RD: Philadelphia, Elsevier Churchill Livingstone. 2010, pp 539-59.

4. Tran TV, Fiset P, Varin F. Pharmacokinetics and pharmacodynamics of cisatracurium after a short infusion in patients under propofol anesthesia. Anesth Analg 1998; 87: 1158-63.

5. Bluestein LS, Stinson LW Jr, Lennon RL, Quessy SN, Wilson RM. Evaluation of cisatracurium, anew neuromuscular blocking agent for tracheal intubation. Can J Anaesth 1996; 43: 925-31.

6. Doenicke AW, Czeslick E, Moss J, Hoernecke R. Onset time, endotracheal intubating conditions, and plasma histamine after cisatracurium and vecuronium administration. Anesth Analg 1998; 87: 434-8.

7. Mellinghoff H, Radbruch L, Diefenbach C, Buzello W. A comparison of cisatracurium and atracurium: onset of neuromuscular block after bolus injection and recovery after subsequent infusion. Anesth Analg 1996; 83: 1072-5.

8. Adamus M, Gabrhelik T, Marek O. Influence of gender on the course of neuromuscular block following a single bolus dose of cisatracurium or rocuronium. Eur J Anaesthesiol 2008; 25: 589-95.

9. Amin AM, Mohammad MY, Ibrahim MF. Comparative study of neuromuscular blocking and hemodynamic effects of rocuronium and cisatracurium under sevoflurane or total intravenous anesthesia. Middle East J Anesthesiol 2009; 20: 39-51.

10. Kisor DF, Schmith VD, Wargin WA, Lien CA, Ornstein E, Cook DR. Importance of the organ-indefendent elimination of cisatracurium. Anesth Analg 1996; 83: 1065-71. 
11. Pearce AC, Casson WR, Jones RM. Factors affecting train-of-four fade. Br J Anaesth 1985; 57: 602-6.

12. Jalkaren L, Meretoja OA. The influence of the duration of isoflurane anaesthesia on neuromuscular effects of mivacurium. Acta Anaesthesiol Scand 1997; 41: 248-51.

13. Wulf H, Kahl M, Ledowski T. Augmentation of neuromuscular blocking effects of cisatracurium during desflurane, sevoflurane, isoflurane or total i.v. anaesthesia. Br J Anaesth 1998; 80: 308-12.

14. Kopman AF. Tactile evaluation of train-of-four count as an indicator of reliability of antagonism of vecuronium- or atracurium-induced neuromuscular blockade. Anesthesiology 1991; 75: 588-93.

15. Kirkegaard H, Heier T, Caldwell JE. Efficacy of tactile-guided reversal from cisatracurium-induced neuromuscular block. Anesthesiology 2002; 96: 45-50.
16. Naguib M, Lien C. Pharmacology of Muscle Relaxants and Their Antagonists. In: Miller's Anesthesia. 7th ed. Edited by Miller RD: Philadelphia, Elsevier Churchill Livingstone. 2010, pp 859-911.

17. Bluestein LS, Stinson LW Jr, Lennon RL, Quessy SN, Wilson RM. Evaluation of cisatracurium, a new neuromuscular blocking agent, for tracheal intubation. Can J Anaesth 1996; 43: 925-31.

18. Kopman AF, Zank LM, Ng J, Neuman GG. Antagonism of cisatracurium and rocuronium block at a tactile train-of-four count 2 : Should quantitative assessment of neuromuscular function be mandatory? Anesth Analg 2004; 98: 102-6.

19. Illman HL, Antila HM, Olkkola KT. Effect of nitrous oxide on cisatracurium infusion demands: a randomized controlled trial. BMC Anesthesiol 2010; 10: 14. 